\title{
A review of pilonidal sinus lesions and a method of treatment
}

\author{
B. P. Flannery \\ F.R.C.S. \\ H. A. KIDD \\ F.R.C.S.E.
}

St Helier Hospital, Carshalton, Surrey

\section{Introduction}

This paper on pilonidal lesions is presented with the object of reviewing the disease and describing a method of treatment introduced by Jacobsen (1959).

A pilonidal sinus is an anomalous condition, in which there may be found a nidus of epithelial and hair cells submerged in the cutaneous tissues of the intergluteal cleft. These elements under certain conditions give rise to symptoms or signs. Their presence is indicated by a number of fine circular pits, which are aligned vertically and are of variable orifice-diameter. They are usually two or three in number, although larger numbers have been described. They extend to the caudal end of the anal cleft, superior to the posterior anal verge beyond which they are not seen. They show no tendency to deviate from a strictly midline position.

The first clinical report of a pilonidal sinus is reputed to have been in 1847 (Dwight \& Maloy, 1953), but Hodge in 1880 is accepted as giving the lesion its name 'pilonidal'.

\section{Incidence}

There is no real age range, although sinuses are usually seen in adolescence and early adulthood. Patients in the seventh decade have required treatment for the first time, and Lewin (1965) has reported thirty-eight occurrences in children under the age of 1 year. Twenty-three of these infants were males and fifteen females. The incidence, normally two male to one female, may vary by as much as $10: 1$. This latter figure is, however, exceptional, and is accounted for by the 1939-45 war years. Hardaway (1961) reported that during the years $1942-45,77,657$ soldiers of the United States Army with pilonidal lesions were treaied. A further 9000 were observed to have lesions which did not require treatment.

The intergluteal cleft is not the sole site of these lesions as was once thought. Hodge in 1880 reported that the removal of hairs from the skin of the feet was practised in those days. Pilonidal sinuses in the interdigital clefts of the hands of barbers has been reported by Patey \& Scarff (1946, $1948,1955)$. Lesions have also been found in the anterior perineum (Smith, 1948), axilla and umbilicus (Aird, 1952) and also in an amputation stump (Shoesmith, 1953. From a review of umbilical sinuses and fistulae (Steck \& Helwig, 1965) thirtyeight sinuses have been histologically identified as pilonidal.

\section{Aetiology}

The cause of pilonidal sinuses has during the last four to five decades been in doubt. For some time, two beliefs supporting a congenital theory of origin were held: (a) remnants of the neural canal became separated off and isolated, thus leading to a sinus tract; and (b) malfusion of the body halves resulted in an ectodermal inclusion site. Supporters of these theories demonstrated a space or canal lying between the coccyx and skin, constant in small embryos (Mallory, 1892) and variable in foetuses (Kooistra, 1942), which normally disappeared at birth. A skin dimple, at times deep enough to be called the 'cisterna' of a sinus is said to be present in $15 \%$ of newly born infants. This dimple usually disappears soon afterwards, but may persist into adult life in less than $3 \%$ of people. There seems, however, to be no direct relationship between these developmental dimples and pilonidal sinus. Nor are other anomalies such as epithelial downgrowths and persistent neurenteric canal remnants, or vestigial secondary sex glands such as the bird's preen gland, of any actiological significance. In the last 20 years, an acquired cause has been widely accepted. This was stimulated by the finding and reporting of Patey \& Scarff (1946) of pilonidal sinuses in barbers' hands seen in the interdigital clefts. Also about this time King (1946) wrote that hairs must be important causative agents as the hairs found in sinuses had their roots nearest the sinus opening. Later Weale (1955) in a histological study of the hairs in pilonidal sinuses suggested that as the roots of these hairs were deeply sited in the tissues, they must be developmentally present in the sinus. He regards the barber's hand sinus as an implantation 
dermoid. Patey \& Scarff contested this idea, and offered the explanation that the cuticular surface arrangement of hair scales was such as to drive hair, root first, into the skin. About the same time, Brearly $(1955,1959)$ introduced a puncture and suction theory, illustrated by manometric tracings of pressure variations in the gluteal cleft area. He displayed this, introducing a needle connected to a capacitance manometer into the subcutaneous tissues of the intergluteal cleft. He pointed out that any force withdrawing skin laterally across the buttocks puts tension on the fascial bands between deep fascia and skin. This is enhanced by gluteal muscle contraction. It also occurs with stretching of buttock skin as induced by flexing the thighs and vibrating the lower limbs. These movements are seen in motorcycle pillion riders and drummers of dance bands.

As the result of pressure variations set up by the factors mentioned above, a suction effect occurs and hairs tend to puncture the skin and proceed by suction to a deeper location carrying epithelium with them. Palmer (1959) offered a theory as to how hairs gain entry to a sinus. At puberty there is a natural enlargement of the buttock and gluteal muscles. He believes that, at this time, there is a lateral stretch directed away from the midline on each side of the raphe. As a result of these forces, a spread or stretching of normal skin orifices occurs, thereby permitting the entrance and packing of hair.

\section{Pathology}

Epithelial cells and hairs form the pilonidal sinus. There is, however, no sure evidence of the depth to which epithelium is present in these lesions. Usually granulation tissue is seen to form the deeper aspect of the sinus tract. In some cases epithelium does not extend beyond 1-2 mm from the surface. It is doubtful whether this is due to epithelial halt or to whether there is destruction of deeper epithelium and replacement by granulation tissue. It is possible that if skin pitting occurs from muscle stretch, then the microscopic opening of surface pits might be compensated by an epithelial downgrowth, preceding the entry, by drilling action, of hairs. Subsequent infection of epithelium and foreign body irritation of hairs would lead to granulation tissue production.

Kooistra (1942) took multiple sections of sinuses and found no evidence of epithelial lining in 39\% of cases. Hair follicles are of doubtful occurrence and some think they never occur. Kooistra, however, reported a $9 \%$ incidence. Palmer found hairs present in $50 \%$ and squamous epithelium in $30 \%$ of ninety-six cases. Patey \& Scarff demonstrated hairs in ten of twenty-one cases and epithelial lining in eight. The hairs may be found either in the sinus or extruding from the pit mouth. Occasionally also a hair may be seen looped over or inverted, entering a pit mouth. They lie in bundles with their axes in the line of the raphe. In colour they are usually dark or brunette, with a barbed feel as if the normal scale arrangement had been exaggerated. Ginger hairs have also been described and blonde hairs are seen in Scandinavians.

\section{Symptomatology}

Most patients complain of either a sinus discharge or of a painful swelling. This latter may resolve to reappear later on after the fashion of a so-called blind boil. Sinus discharge is usually secondary to a bout of infection, and may be accompanied by a crop of small follicular pustules. These may also be secondary to the sinus discharge, but commonly are the result of irritation and infection produced by strapping of the zinc oxide type to which some skins are sensitive. Cleansing with suitable agents, methylated spirit or cetavlon, etc., and avoidance of strapping heals the condition. The discharge from a sinus fluctuates and to a degree is dependent on the quantity of infected epithelium contained within the tracts. Not infrequently the sinus dries up and may stay healed without the need for further treatment. More usually it recurs, and it seems that chemotherapy has no effect on the closure rates of these sinuses. More rarely patients will complain of bleeding, and this is often due to scratching. At other times the patient complains of discomfort when sitting.

It is perhaps salutary to remember that pilonidal sinuses are found by accident in patients who have had no symptoms from them, and who may have been totally unaware of their presence. In such cases treatment is not justified.

\section{Treatment}

Prophylactic. There are no measures that will with certainty prevent pilonidal formation, but the incidence of recurrent infection can be lowered by adherence to the following hygienic measures: (a) hairy patients would be wise, particularly in warm and moist conditions, to shave frequently the intergluteal area, perhaps every 4-5 days; (b) all hairs round sinus openings to be removed, either by shaving or scrubbing or with epilation creams; (c) careful anal toilet; (d) soap and water, or detergent cleansing of the intergluteal area with thorough drying; (e) in certain exceptional circumstances, the avoidance of occupational hazards, e.g. driving for prolonged periods; and (f) radiation epilation, although this is of limited value. 
Curative. The primary aim of treatment is to eradicate the lesion in the simplest and most effective way. This implies minimal interference with local anatomy and function. Many ways of treating this condition have been described, as briefly outlined below.

(i) Simple incision. This is usually reserved for the acute infective swelling, on one or other side of the median raphe, and more usually superior than inferior to it. Recurrence is the rule, however, as these lesions are not simple pyogenic abscesses. Unless relief of pain is urgent, it is better to treat these infections as a blind boil with local applications. Incision may otherwise be followed by a persistently discharging sinus, unless drainage is effected via a mid-line sinus opening.

(ii) Simple laying open. This implies a mid-line incision, through the mouths of the pits and is effective in those cases of so-called raphe cannulization where infection spreads from pit to pit.

(iii) Open packing. In some instances elliptical excision of the lesion is done and the resulting space is packed to encourage granulations to form. These are eventually covered with epithelium, the healing process on average taking 86 days (Berkowitz, 1949).

(iv) Partial closure. After excision, a partial primary suture of the skin and underlying tissue is performed, but all tension should be avoided. On average these wounds take 50 days to heal completely (Korb, 1951). This time may be shortened by applying split skin grafts at the time of suture or a few days afterwards if no signs of tension necrosis develop. This type of skin graft, however, does not wear well in the face of the stresses and stretch to which the anatomical part is subject.

(v) Primary excision and closure has been advocated and condemned with equal enthusiasm. Reported results vary from $94.5 \%$ success (Oldham, 1945, 1950) to $100 \%$ failure (Rogers \& Hall, $1935)$ in recurrent cases. Brearly (1955) reiterates and stresses the basic principles on which success depends: (i) the elimination of dead space which would fill with haematoma or serous collections, (ii) the avoidance of infection, and (iii) the problem of later hair intrusion.

Adequate closure depends on the above factors, and may be effected by the method of Oldham or by the use of buried catgut figure-of-eight sutures (Rains, 1959) or by through and through occlusive sutures.

Analysis of the various methods of suturing indicate variable success rates (Wenger,1950; Kleiman, 1950), although since 1953 there has been a trend away from block excision (Swinton \& Contreras, 1952) towards limited resection and marsupialization, which has been regarded as the simplest way of disposing of the lesion without disturbing anatomy. In a series of 359 cases using this technique, in the majority of them Lawrence \& Baker (1951) laid open the sinus in its full length with an incision as midline as possible. Other lateral sinuses or tracts were treated similarly. All infected chronic granulation tissue and hair nests were curetted away; any lateral pockets were laid open and the sinus lining curetted down to its base of scar tissue. Overhanging skin edges were conservatively excised. These were then sutured to the lateral margins of the scar tissue sinus bed and to any epithelial islets (Shaner, 1957), which in the course of healing becomes covered over with epithelium. Overall healing time is 6 weeks.

(vi) Rotation flaps and skin grafting are of use in the cases where multiple sinuses and lateral tracts in recurrent cases are widely excised, leaving a median area too large to suture.

Estlander flaps were popularized by Davies \& Starr (1945), who on the concept that the median sacral groove is virtually avascular decried closure by suture after primary excision. Whilst there is little general use or need for this operation there are circumstances where it is practical to use it.

(vii) Phenol injection is a method described by Maurice \& Greenwood (1964), whose intention was primarily to inject the sinuses with phenol as a prelude to laying them open. However, a trial series of cases with phenol injection alone was undertaken. Basically it entailed the injection of phenol without pressure (which is of obvious importance) into the main sinus tract. The surrounding skin is first protected with heavy layering of petroleum jelly. Residual phenol is expressed from the sinus tracts and swabbed away, the procedures being repeated twice to permit of an overall phenol-tissue contact time of $3 \mathrm{~min}$.

(viii) Diathermy coagulation is the method presented by Jacobsen (1959) and allows the objective of destroying the lesion to be carried out with the least possible tissue sacrifice, interference with the sacro-coccygeal fascia or with the intergluteal depression. For practical purposes, he divides the lesion into three categories; those with a distal aperture, those with a series of pin-point openings, and the remainder having one or more draining sinuses. Recurrent sinuses are included in the latter. Whilst he uses low spinal or saddle block anaesthesia, and in some cases local block, our patients have been anaesthetized and intubated, lying face down with chest and thighs supported on pillows. As the sinuses are usually associated with inferiorly placed pits, one of these, or the distal aperture, is used to insert the diathermy electrode ; they may need dilation with a probe. Jacobsen uses a bipolar uterine cervical coagulator, but we 


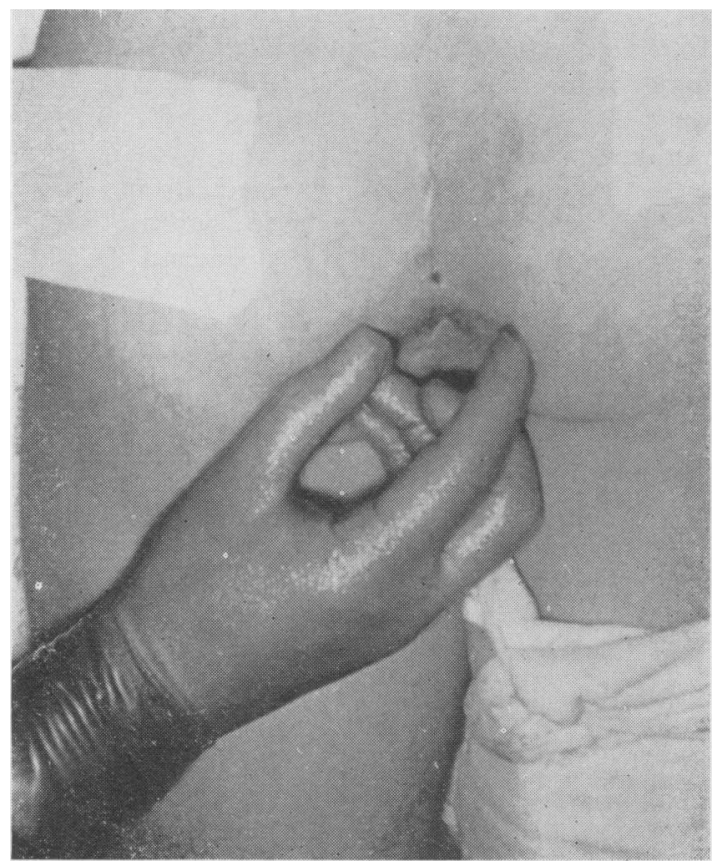

FIG. 1. Note midline sinus orifice.

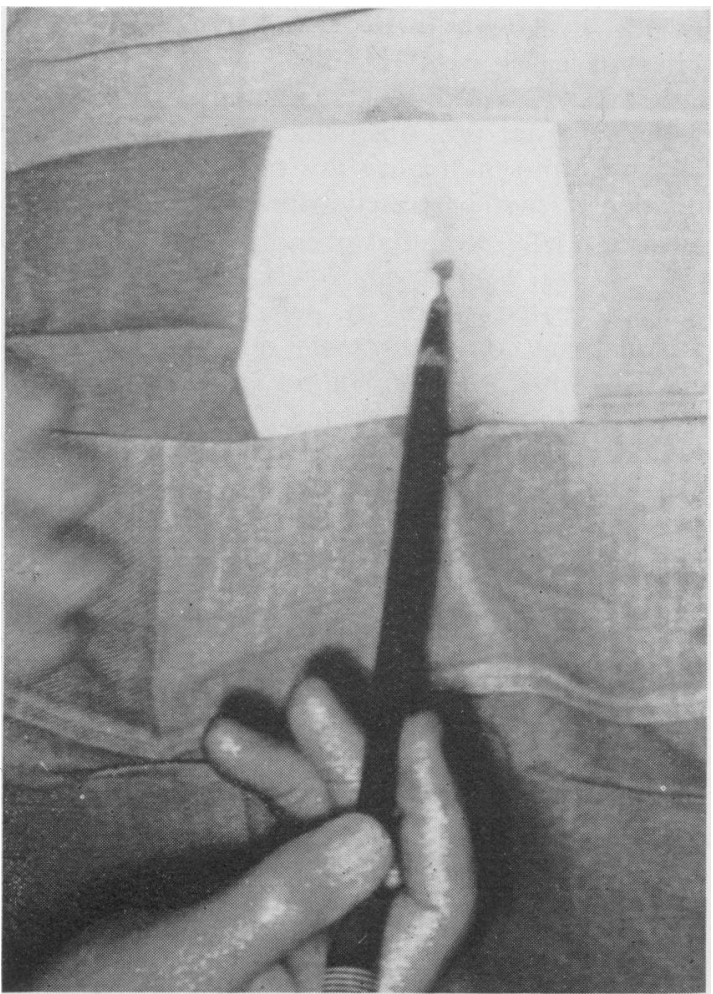

FIG. 2. To illustrate diathermy point within sinus tract.

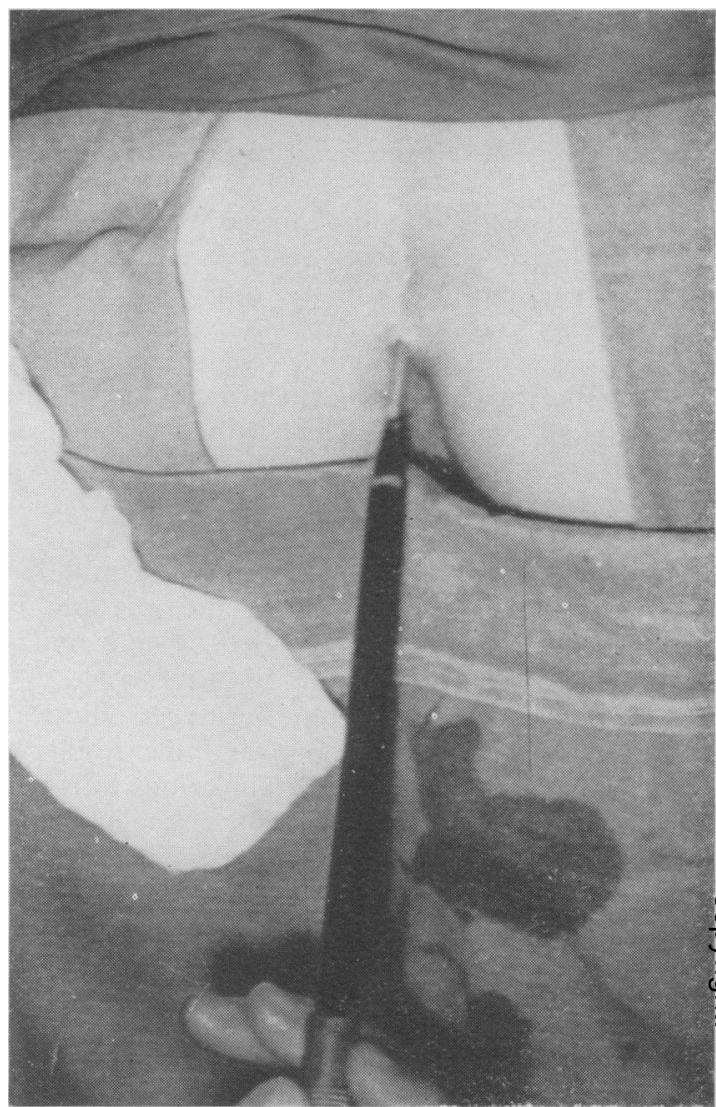

Fig. 3. Note rubber sheath about the needle and steam raising the orifice edge prior to escape.

have used a diathermy point which is passed into the pits and separated from the insulated handle by a small core of rubber tubing. This seals off the orifices. The coagulation current is operated with a foot switch and maintained for about 4-6 sec until the tissues blow up with an effervescent bubbling around the electrode, indicating the escape of steam. Then the skin over the area is divided with the cutting current $0.5 \mathrm{~cm}$ beyond both ends to make a saucerized depression. By the agency of this heat, the sinus epithelium is destroyed and intra- and extracellular water converted into steam which sterilizes and destroys where it goes. Cell destruction beyond the sinus and any communicating tract is limited by the insulating barrier of the coagulated epithelium. When a series of pin-point openings is the only indication of the disease, the skin is divided through these openings down to the deep fascia; the tracts are so small that the narrow diathermy instrument destroys them in its path. When sinuses are present, they 
are treated in the same way with the diathermy unit and cutting instruments. For recurrent sinuses, diathermy is not used as there should be no epithelium to destroy. Probes are passed into the sinuses and then they are laid open with the scalpel blade. The pre-sacral fascia is exposed in the midline for a width of nearly a quarter of an inch and epithelialization retarded by rolling the skin edges into the subcutaneous tissues and holding it there with nylon sutures attached to buttons. When infection has settled, the skin edges may be freed and epithelialization encouraged.

As a result of the diathermy current the sinus is converted into a burn and it is treated as such, with the object of separating off the slough and promoting a clean surface for epithelium to grow over.

Post-operative care is very important. Whilst Jacobsen does his first post-operative dressing after the patient has left hospital, we have kept our patients for 10-14 days, until a clean granuation wound is well evident. Patients are encouraged to have daily baths and to scrub lightly the surrounding skin with a brush to remove hairs. At all outpatient attendances the healing epithelium is carefully observed (with a glass if need be) for midline cracks wherein hairs may come to lie. The cracks are often associated with bridging, the epithelium growing faster than the granulation tissue beneath can fill up the hiatus. By dividing the epithelium in the line of the crack, it thus falls down onto the underlying tissue preserving the depth of the sacrococcygeal depression.

Malignant change has been recorded in cases of all long-standing sinuses, fistulae, scars, burns, ulcers and osteomyelitis (Arons et al., 1965). These authors illustrated a case of squamous carcinoma occurring in a 32-year-old white patient with a 7-year history of pilonidal sinus. This is exceptional. Cleveland and Green (1964) have reported thirteen cases found in American and overseas publications. It is of interest that in all but two of these patients the history lay between 15 and 43 years, and that the age of onset of the malignancy was between the fifth and seventh decades. Though nearly all these thirteen subjects have had some surgical procedure, ultimate recurrence was the rule.

Since 1953, 104 cases have been treated on our surgical firm at St Helier Hospital. They have fallen into the following category:

$\begin{array}{cccc}\text { No. of cases } & \text { Previously treated } & \text { Primary cases } \\ 104 & \text { Once } & 15 & 80 \\ & \text { Twice } & 6 & \\ & \text { Thrice } & 3 & \end{array}$

The operative methods used have been:

\section{Operation}

Diathermy

Excision and primary closure

Excision and closure with single or double Estland flaps

Delayed epithelialization by skin edge inversion
No. of cases

62

30

6
Follow-up has been by out-patient attendance for a minimum of 2 years and a maximum of 9 years since operation. The overall recurrence rate has been $19 \%$. Of the sixty-two cases treated with diathermy, six, or $9.6 \%$, have recurred.

\section{Summary}

Pilonidal sinus is a common complaint occurring in the young. Although mortality and morbidity are minimal, economic effects by reason of lost work hours are significant.

Most cases are explained on an acquired basis of aetiology, although occasionally it is difficult to exclude a developmental association.

Whilst most cases are seen in the intergluteal cleft other sites of origin have been mentioned.

The treatment by diathermy, after the method of Jacobsen, was employed in sixty-two cases with a recurrence on a 2-9 year follow-up of six cases. The importance of post-operative care is stressed.

\section{References}

AIRD, I. (1952) Pilonidal sinus of axilla. Brit. med. J. i, 901. Arons, M.S., LYNCH, J.B., Lewis, S.R. \& BloCker, T.G. (1965) Scar tissue carcinoma. Ann. Surg. 161, 170.

Berkowitz, J. (1949) Sacrococcygeal pilonidal cyst. Amer. J. Surg. 77, 477.

Brearly, R. (1955) Pilonidal sinus. A new theory of origin. Brit. J. Surg. 43, 62.

Cleveland, B.P. \& Green, W.O. (1964) Squamous cell carcinoma arising in a pilonidal sinus. Surgery, 55, 381.

Davies, L.S. \& StarR, K. (1945) Infected pilondial sinus. Surg. Gynec. Obstet. 81, 309.

Dwight, R.W. \& Maloy, J.K. (1953) Pilonidal sinus: experience with 449 cases. New Engl. J. Med. 249, 926.

HaRDaway, R. (1961) Pilonidal cyst - mis-named, misunderstood and mis-treated. J. med. Ass. Georgia, 50, 51.

Hodge, A.M. (1880) Pilonidal sinus. Boston Med. Surg. J. $103,465$.

JACOBSEN, P. (1959) Pilonidal disease: management without excision. Amer. Acad. G.P. xix, No. 3.

KING, E.S. (1946) The nature of the pilonidal sinus. Aust. N. Z. J. Surg. 16, 182.

Kleiman, A. (1950) Pilonidal cyst: comparison of surgical treatment. Surgery, 28, 851 .

Kooistra, H.P. (1942) Pilonidal sinuses: review of literature and reports of 350 cases. Amer. J. Surg. 55, 3.

KORB, J.H. (1951) Infected pilonidal cysts: a simplified method of treatment. Military Surgeon, 108, 29.

LAWRENCE, K.B. \& BAKER, W.J. (1951) The marsupialisation operation for pilonidal sinus. New Engl. J. Med. 245, 134.

LewIN, R.A. (1965) Pilonidal sinus in infancy. Paediatrics, 35, 796 . 
MalloRY, F.B. (1892) Sacrococcygeal dimples, sinuses and cysts. Amer. J. med. Sci. 103, 263.

Maurice, B.A. \& Greenwood, R.K. (1964) A conservative treatment of pilonidal sinus. Brit. J. Surg. 51, 510.

Oldham, J.B. (1945) Sacrococcygeal (pilonidal) sinus. Med. Press, 214, 248.

Oldham, J.B. (1950) Pilonidal sinus. Brit. Surg. Pract. 7, 417.

Palmer, W.H. (1959) Pilonidal disease: a new concept of pathogenesis. Diseases of the Colon and Rectum, Vol. 2, p. 303. Philadelphia.

Patey, D.H. \& SCarf, R.S. (1946) Pathology of post-anal pilonidal sinus. Its bearing on treatment. Lancet, ii, 484.

Patey, D.H. \& Scarf, R.S. (1948) Pilonidal sinus in barber's hand with observations on post-anal pilonidal sinus. Lancet, ii, 13.

Patey, D.H. \& Scarf, R.S. (1955) The hair of the pilonidal sinus (Letter to the Editor). Lancet, i, 772.

RaINS, A.J. (1959) Treatment of pilonidal sinus by excision and primary closure. Brit. med. $J$. ii, 171 .
Rogers, H. \& Hall, M.G. (1935) Pilonidal sınus: surgical treatment and pathologic structure. Arch. Surg. 31, 742.

Shaner, W. (1957) Treatment of pilonidal disease by marsupialisation. Winconsin med. J. 56(6), 281.

Shoesmith, J.H. (1953) Pilonidal sinus in an above knee amputation stump. Lancet, ii, 378.

Sмiтh, T.E. (1948) Anterior or perineal pilonidal sinus. J. Amer. med. Ass. 136, 973.

Steck, W.D. \& Helwig, E.B. (1965) Umbilical granulomas, pilonidal disease and the urachus. Surg. Gynec. Obstet. 120, 1043.

Swinton, N.W. \& Contreras, O. (1952) Pilonidal sinus. Proc. Roy. Soc. Med. Suppl. 107, 110.

Terry, J.L., Gainsford, J.C. \& Hanna, D.C. (1961) Pilonidal sinus carcinoma. Amer. J. Surg. 102, 465.

Weale, F.E. (1955) A comparison of barber's and post-anal pilonidal sinuses. Lancet, i, 230.

WENGER, D.S. (1950) Pilonidal cysts: their origin and treatment. Amer. J. Surg. 80, 243. 